\title{
Discovery and Preclinical Development of Netarsudil, a Novel Ocular Hypotensive Agent for the Treatment of Glaucoma
}

\author{
Cheng-Wen Lin,, Bryan Sherman,, Lori A. Moore, Carmen L. Laethem,, Da-Wen Lu, \\ Padmanabhan P. Pattabiraman,, ${ }^{3, *}$ Ponugoti Vasantha Rao, ${ }^{3}$ Mitchell A. deLong, ${ }^{1}$ and Casey C. Kopczynski ${ }^{1}$
}

\begin{abstract}
Purpose: Rho-associated protein kinase (ROCK) inhibitors lower intraocular pressure (IOP) by increasing aqueous outflow through the trabecular meshwork (TM). The preclinical characterization of netarsudil, a new ROCK/norepinephrine transporter (NET) inhibitor currently in clinical development, is presented herein.

Methods: The kinase inhibitory activity of netarsudil was compared to its esterase metabolite, netarsudil-M1, and 3 other ROCK inhibitors using a commercially available kinase assay kit. Disruption of actin stress fibers was measured in primary porcine TM cells and disruption of focal adhesions in transformed human TM (HTM) cells. Induction of fibrosis markers after exposure to transforming growth factor- $\beta 2$ (TGF- $\beta 2$ ) was conducted in primary HTM cells. Ocular hypotensive activity and tolerability of topical formulations were evaluated in normotensive Dutch Belted rabbits and Formosan Rock monkeys. In vitro corneal metabolism assays were conducted using dog, pig, rabbit, monkey, and human corneas. In vivo ocular pharmacokinetics was studied in Dutch Belted rabbits.

Results: Netarsudil inhibited kinases ROCK1 and ROCK2 with a $K_{\mathrm{i}}$ of $1 \mathrm{nM}$ each, disrupted actin stress fibers and focal adhesions in $\mathrm{TM}$ cells with $\mathrm{IC}_{50} \mathrm{~S}$ of 79 and $16 \mathrm{nM}$, respectively, and blocked the profibrotic effects of TGF- 32 in HTM cells. Netarsudil produced large reductions in IOP in rabbits and monkeys that were sustained for at least $24 \mathrm{~h}$ after once daily dosing, with transient, mild hyperemia observed as the only adverse effect.

Conclusion: Netarsudil is a novel ROCK/NET inhibitor with high potency in biochemical and cell-based assays, an ability to produce large and durable IOP reductions in animal models, and favorable pharmacokinetic and ocular tolerability profiles.
\end{abstract}

Keywords: Rho kinase, glaucoma, intraocular pressure, trabecular meshwork, netarsudil

\section{Introduction}

$\mathbf{G}$ LAUCOMA IS A LEADING CAUSE of irreversible blindness that affects $>60$ million people worldwide. ${ }^{1,2}$ Glaucoma can arise through various etiologies, but vision loss is ultimately due to the progressive death of retinal ganglion cells and related damage to the optic nerve. ${ }^{3}$ Currently, the only therapeutic intervention demonstrated to slow damage to the optic nerve and preserve vision is the reduction of intraocular pressure (IOP). ${ }^{4}$

In a healthy eye, trabecular outflow is the main drainage pathway for aqueous humor (AH). IOP is maintained within a narrow range through pressure-sensitive regulation of aqueous outflow. ${ }^{5}$ In a glaucomatous eye, IOP becomes elevated as a result of an abnormally high resistance to outflow through the trabecular pathway. ${ }^{6}$ The causes of increased outflow resistance are not fully understood, but it appears to involve an increase in the contractile tone and stiffness of the trabecular meshwork (TM), changes in extracellular matrix deposition, and changes in the permeability of the inner wall of Schlemm's canal. ${ }^{5}$

The most commonly used glaucoma medications do not specifically target the diseased TM, but lower IOP primarily by either increasing aqueous outflow through the uveoscleral

\footnotetext{
${ }^{1}$ Aerie Pharmaceuticals, Inc., Durham, North Carolina.

${ }^{2}$ National Defense Medical Center, Taipei City, Taiwan.

${ }^{3}$ Department of Ophthalmology, Duke University School of Medicine, Durham, North Carolina.

*Current affiliation: Department of Ophthalmology, Case Western Reserve University, Cleveland, Ohio.
}

(C) Cheng-Wen Lin et al. 2018; Published by Mary Ann Liebert, Inc. This is an Open Access article distributed under the terms of the Creative Commons Attribution License, which permits unrestricted use, distribution, and reproduction in any medium, provided the original work is properly cited. 
outflow pathway (prostaglandin analogs and alpha agonists) or decreasing aqueous production (beta blockers, carbonic anhydrase inhibitors, and alpha agonists). ${ }^{7,8}$ Pilocarpine, a muscarinic receptor agonist, lowers IOP by increasing trabecular outflow facility, but its pharmacological target tissue is the ciliary muscle, not the TM. Pilocarpine-induced contraction of the ciliary muscle changes the shape of the outflow pathway such that the juxtacanalicular portion of the TM expands and the lumen of Schlemm's canal widens, reducing resistance to outflow. ${ }^{9,10}$

To develop new glaucoma medications, a number of therapeutic targets are being pursued that directly address the cause of elevated IOP: the diseased trabecular outflow pathway. ${ }^{11}$ Rho-associated protein kinase (ROCK) inhibitors represent a new class of trabecular outflow drugs currently in clinical development. ROCK is a serine/threonine kinase that serves as an important downstream effector of Rho GTPase. ROCK activity in TM and Schlemm's canal cells drives actomyosin contraction, promotes extracellular matrix production, and increases cell stiffness. ${ }^{12}$ Inhibitors of ROCK, conversely, reduce cell contraction, decrease expression of fibrosis-related proteins, and reduce cell stiffness in cultured TM and Schlemm's canal cells. In animal models, ROCK inhibitors have been shown to increase trabecular outflow facility and thereby lower IOP. ${ }^{12,13}$

The therapeutic potential of ROCK inhibitors was initially demonstrated using the small molecule inhibitor $\mathrm{Y}$ 27632, which was shown to lower IOP in rabbits upon topical ocular application, ${ }^{14}$ relax precontracted TM tissue, ${ }^{15}$ and increase trabecular outflow facility in perfused enucleated porcine eyes. ${ }^{16}$ Similar results have since been reported for other ROCK inhibitors, some of which have been shown to lower IOP in clinical trials. ${ }^{17}$ Recently, the ROCK inhibitor ripasudil earned regulatory approval in Japan for the reduction of IOP in subjects with glaucoma. ${ }^{18}$

Aerie Pharmaceuticals initiated its Rho kinase drug discovery program in 2006 . The goal was to identify effective and well-tolerated ROCK inhibitors with a durable IOPlowering effect. This effort resulted in the discovery of a new class of amino-isoquinoline amide ROCK inhibitors. ${ }^{19}$ In addition to being highly potent inhibitors of ROCK, the most effective compounds in this class also had inhibitory activity against the norepinephrine transporter (NET). From this new class of ROCK/NET inhibitors, netarsudil (also known as AR-13324) was selected for clinical development.

Consistent with its ROCK inhibitory activity, topical administration of netarsudil has been shown to lower IOP in animal studies by increasing trabecular outflow facility. ${ }^{20,21}$ Netarsudil has also been shown to decrease production of $\mathrm{AH}$ in monkeys ${ }^{16}$ and to decrease episcleral venous pressure in rabbits. ${ }^{22}$ These secondary IOP-lowering mechanisms have not been reported for other ROCK inhibitors, and thus may be related to netarsudil's NET inhibitory activity. Importantly, netarsudil has also been tested in human donor eyes and shown to increase trabecular outflow facility, increase the effective filtration area of the TM, cause expansion of the TM tissue, and dilate episcleral veins. ${ }^{23}$

In Phase 2 and Phase 3 clinical studies, once daily dosing of netarsudil has demonstrated significant IOP lowering and a favorable safety profile in subjects with glaucoma and ocular hypertension. ${ }^{24-26}$ This article presents the preclinical pharmacological and pharmacokinetic studies that identified netarsudil as a promising clinical candidate, and provides some insight into the clinical pharmacology of the molecule.

\section{Methods}

\section{Test articles}

Netarsudil, its esterase metabolite netarsudil-M1, and AR12286 were synthesized at Aerie Pharmaceuticals. ROCK inhibitors fasudil and Y-27632 were purchased from Sigma (St. Louis, MO). ${ }^{14} \mathrm{C}$-netarsudil and ${ }^{3} \mathrm{H}-\mathrm{AR}-12286$ were prepared by Quotient Bioresearch (Cambridgeshire, United Kingdom) by incorporating a ${ }^{14} \mathrm{C}$ label into the $\beta$ position of the amino acid portion of netarsudil and a ${ }^{3} \mathrm{H}$ label at the $\mathrm{C}-5$ of the isoquinolone, respectively. The chemical structures are presented in Fig. 1.

\section{Biochemical and cell-based assays}

Protein kinase assays were conducted using serially diluted test compound as previously described. ${ }^{19}$ In brief, protein kinase activity was quantitated in 96-well white, flatbottom, half-area, nonbinding assay plates (Corning No. 3642) using Promega's Kinase-Glo ${ }^{\mathrm{TM}}$ Luminescent Kinase Assay Kit (Promega, Madison, WI) according to included directions. The kinases ROCK1, ROCK2, protein kinase Ctheta (PKC-theta), and calcium/calmodulin-dependent protein kinase II Alpha (CAMK2A) were purchased from Invitrogen/Life Technologies (Waltham, MA). Protein kinase A (PKA) and myotonic dystrophy kinase-related CDC42-binding kinase alpha (MRCKA) were purchased from Upstate (Lake Placid, NY).

Cell-based assays measuring disruption of actin stress fibers and focal adhesions were conducted using highcontent screening in primary porcine TM (PTM) cells and in transformed human TM (HTM) cells, respectively, as previously described. ${ }^{19}$ In brief, PTM cells were isolated from freshly obtained enucleated porcine eyes following the procedure by Rao and Epstein. ${ }^{27}$ Immortalized HTM cells (TM-1) were obtained through a kind gift from Donna Peters (Department of Ophthalmology and Visual Sciences, University of Wisconsin). Cells were grown on fibronectincoated glass-bottom 96-well plates, incubated for $6 \mathrm{~h}$ in media containing the serially diluted test compound, formaldehyde fixed, triton solubilized, and stained. PTM cells were stained with Alexa Fluor ${ }^{\circledR} 488$ phalloidin and Hoechst 33342 to reveal F-actin and nuclei, respectively. HTM cells were stained with mouse anti-paxillin antibody/Alexa Fluor 488 goat-anti-mouse IgG and Hoechst 33342 to reveal focal adhesions and nuclei, respectively. All staining reagents were obtained through Invitrogen/Life Technologies. Images were collected on an INCell 1000 imager (GE Healthcare, Marlborough, MA) with a $20 \times$ objective, and actin fiber length and total area of focal adhesions were measured using custom algorithms developed using the INCell Developer Toolbox, v1.6. Statistical calculations $\left(\mathrm{IC}_{50}\right)$ were performed using a 3-parameter Dose Response Inhibition algorithm in GraphPad Prism.

Cell-based assays measuring the expression of fibrogenic markers were conducted in primary HTM cells cultured from TM tissue isolated from donor corneal rings as previously described. ${ }^{28}$ HTM cells from passages 4-6 were used in 2 separate experiments. Cells were grown on gelatin $(2 \%)$ coated coverslips until they were semi-confluent. Serumstarved HTM cells $(24 \mathrm{~h})$ were treated with $8 \mathrm{ng} / \mathrm{mL}$ human recombinant transforming growth factor- $\beta 2$ (TGF- $\beta 2$ ) (SigmaAldrich, St Louis MO), $500 \mathrm{nM}$ netarsudil, $8 \mathrm{ng} / \mathrm{mL}$ TGF- $\beta 2$ 
FIG. 1. Structures of test compounds. NETi, norepinephrine transporter inhibitor; ROCKi, Rho-associated protein kinase inhibitor.

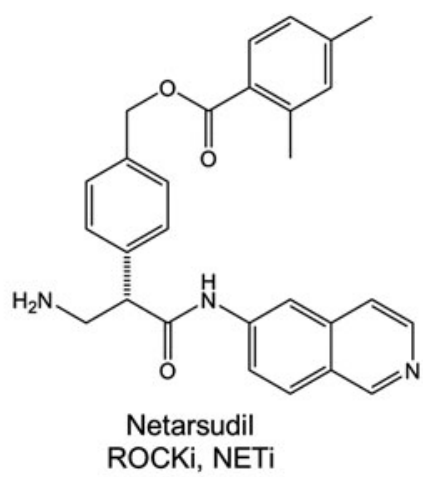<smiles>[M]O[R16]([H])([H])O[Na]</smiles><smiles>[R20][R20]([R20])([H])NC(=O)Nc1ccc2c(O)nccc2c1</smiles><smiles>[R20]OC([Y20])[R20]</smiles>

plus $500 \mathrm{nM}$ netarsudil, or vehicle for $24 \mathrm{~h}$. The cells were then assessed for induction of the fibrogenic markers $\alpha$-smooth muscle actin ( $\alpha$-SMA), Collagen I, and fibroblast-specific protein 1 (FSP1) using immunofluorescence staining as previously described. ${ }^{29}$ Mouse monoclonal antibody against $\alpha$ SMA was purchased from Sigma-Aldrich, rabbit anti-FSP1 antibody from EMD Millipore (Billerica, MA), and rabbit antiCollagen I antibody from Abcam (Cambridge, MA).

\section{Efficacy and tolerability in animal models}

Ocular hypotensive activity and tolerability were evaluated in Dutch Belted rabbits ( $n=10-12$ /group) and Formosan Rock monkeys ( $n=6 /$ group). Rabbits were conscious during IOP measurements and ocular examinations, whereas monkeys were lightly anesthetized with ketamine $(5 \mathrm{mg} / \mathrm{kg}$, intramuscular). Test articles were topically administered as $30 \mu \mathrm{L}$ drops to 1 eye of each animal once daily (AM) for 3 days, with the fellow untreated eye serving as the control. IOP was determined for both eyes before test article administration and at times $1,2,4,8$, and $24 \mathrm{~h}$ (rabbits) or 4, 8, and $24 \mathrm{~h}$ (monkeys) after each morning dose using a Model 30 Classic $^{\mathrm{TM}}$ pneumatonometer (Reichert, Inc., Depew, NY). Three independent IOP measurements were obtained and averaged for each eye at each time point. A modified Draize scale was used to score ocular tolerability. ${ }^{30}$ Hyperemia was scored on a 0 to 3 scale (none to severe). Probability comparisons for the difference in IOP between treated and untreated eyes were performed for each time point using a 2-tailed paired Student's $t$-test. A critical $P$ value of $P<0.05$ was used to determine statistical significance. Statistical calculations were performed using XLfit (Version 4.2.1; IDBS, Guildford, United Kingdom). Animal testing was conducted in accordance with the ARVO Statement for the Use of Animals in Ophthalmic and Vision Research.

\section{Pharmacokinetics}

Corneal metabolism. Enucleated pig eyes $(n=3)$ were harvested at a local abattoir, stored on ice, and used within
$4 \mathrm{~h}$ of slaughter. For eyes harvested from beagle dogs $(n=3$; Calvert Laboratories, Pittston, PA), Dutch Belted rabbits ( $n=3$; Robinson Services, Mockesville, NC), and cynomolgus monkeys ( $n=4$; Covance, Madison, WI), intact globes were stored in K-Sol corneal preservation buffer ${ }^{31}$ under cold conditions and used within $24 \mathrm{~h}$ of sacrifice. Human corneas $(n=3)$ were acquired from The Eye Bank for Sight Restoration (New York, NY). The weights of the corneal punches were approximately the same for the dog, pig, human, and rabbit, whereas monkey corneal punches were approximately half of the weight of the others. Corneal punches were stored in phosphate-buffered saline and used within $1 \mathrm{~h}$ of preparation.

Corneal metabolism assays were initiated by adding $1 \mathrm{~mL}$ of $400 \mu \mathrm{M}$ netarsudil mesylate in borate-mannitol assay buffer, pH 6.5 to wells containing individual corneal punches in $1 \mathrm{~mL}$ assay buffer followed by thorough trituration. Samples were incubated at $37^{\circ} \mathrm{C}$ and reactions were subsequently terminated at appropriate time intervals by transferring a $100 \mu \mathrm{L}$ aliquot of solution to an equal volume of cold acetonitrile followed by thorough trituration. The samples were centrifuged at $10,000 \mathrm{~g}$ for $10 \mathrm{~min}$ and the supernatants analyzed by high performance liquid chromatography (HPLC) using a Waters Alliance 2695 HPLC (Milford, MA) equipped with a Symmetry C18 4.6×75 mm $3.5 \mu \mathrm{m}$ column. Netarsudil peak areas were integrated using Mass Lynx V4 (Waters Corporation, Milford, MA).

Ocular metabolism. Topical ocular doses of $0.02 \%$ netarsudil mesylate ( $35 \mu \mathrm{L}$ drop) were administered to both eyes of 3 male New Zealand rabbits in each of 4 groups. In groups 1 and 2, the test article was dosed only once, and $100 \mu \mathrm{L}$ samples of $\mathrm{AH}$ were taken from each eye by paracentesis at 4 or $6 \mathrm{~h}$ postdose, respectively. In groups 3 and 4 , the test article was dosed once daily for 3 or 4 days, respectively, and $100 \mu \mathrm{L}$ samples of $\mathrm{AH}$ were taken $4 \mathrm{~h}$ after dosing. Levels of netarsudil and its metabolite netarsudilM1 were measured in the samples by HPLC/mass 
Table 1. In Vitro Potency of Rho-Associated Protein Kinase Inhibitors (nM)

\begin{tabular}{|c|c|c|c|c|c|c|c|c|}
\hline Compound & $R O C K 1 \mathrm{~K}_{i}$ & $R O C K 2 \mathrm{~K}_{i}$ & $P K A \mathrm{~K}_{i}$ & $P K C T \mathrm{~K}_{i}$ & $M R C K A \mathrm{~K}_{i}$ & $C A M 2 A \mathrm{~K}_{i}$ & $P T M I C_{50}$ & $H T M I C_{50}$ \\
\hline Netarsudil & 1 & 1 & 5 & 92 & 129 & 5,312 & 79 & 16 \\
\hline Netarsudil-M1 & 0.2 & 0.2 & 1 & 27 & 7 & 13,689 & 22 & 3 \\
\hline AR-12286 & 2 & 2 & 69 & 9,322 & 28 & 5,855 & 924 & 818 \\
\hline Y27632 & 22 & 41 & 21,006 & 413 & 485 & 16,863 & 9,970 & 1,738 \\
\hline Fasudil & 76 & 47 & 216 & 3,162 & 5,983 & 3,162 & 10,060 & 3,942 \\
\hline
\end{tabular}

Values represent the average of $\geq 3$ replicate experiments.

CAM2A, calcium/calmodulin-dependent protein kinase $2 \mathrm{~A}$; HTM, human trabecular meshwork; $\mathrm{IC}_{50}$, half maximal inhibitory concentration; $K_{\mathrm{i}}$, inhibition constant; MRCKA, myotonic dystrophy kinase-related CDC42-binding kinase A; PKA, protein kinase A; PKCT, protein kinase C, theta; PTM, porcine trabecular meshwork; ROCK1, Rho-associated protein kinase 1; ROCK2, Rho-associated protein kinase 2.

spectrometry (HPLC/MS) with a lower limit of quantitation of $0.1 \mathrm{ng} / \mathrm{mL}$ for each analyte.

Absorption and distribution. A single topical ocular dose of $0.02 \%{ }^{14} \mathrm{C}$-netarsudil mesylate $(35 \mu \mathrm{L}$ drop) was administered to both eyes of 3 male Dutch Belted rabbits in each of 7 groups. At $0.25,0.5,1,4,8,24$, and $48 \mathrm{~h}$ postdose, the following samples were harvested from each group: whole blood, derived plasma, AH, vitreous humor, cornea, conjunctiva, lens, iris/ ciliary body, retina-choroid-plexus, liver, and kidneys. All samples were assayed for total radioactivity. A study of the same design was conducted for AR-12286, using a single topical ocular dose of $0.5 \%{ }^{3} \mathrm{H}-\mathrm{AR}-12286$ (35 $\mu \mathrm{L}$ drop).

\section{Results}

\section{In vitro activity}

Netarsudil inhibitory activity against the 2 described isoforms of Rho kinase, ROCK1 and ROCK2, in addition to the additional kinases PKA, MRCKA, PKC-theta, and CAMK2A is presented in Table 1. Also tested were netarsudil-M1, the primary metabolite of netarsudil, and the ROCK inhibitors AR12286, Y-27632, and fasudil. All 5 compounds demonstrated significant inhibitory activity against ROCK1 and ROCK2, with the order of potency from highest to lowest being netarsudil-M1 >netarsudil $>$ AR-12286 $>$ Y-27632 $>$ fasudil. These data reveal that netarsudil-M1 is an active metabolite with 5-fold greater activity against Rho kinase than netarsudil.

The same compounds were tested in cell-based assays for their ability to disrupt actin stress fibers and focal adhesions in PTM cells and HTM cells, respectively (Table 1 and Fig. 2). The rank order of potency was the same as in the
ROCK biochemical assays, with netarsudil-M1 demonstrating $\sim 5$-fold greater activity than netarsudil for disruption of actin stress fibers and focal adhesions.

The ability of netarsudil to block TGF- $\beta 2$-induced expression of fibrogenic markers was evaluated in primary HTM cells (Fig. 3). HTM cells treated with TGF- $\beta 2$ alone for $24 \mathrm{~h}$ showed increased immunostaining for $\alpha$-SMA, FSP1, and Collagen I compared to untreated cells. In contrast, the simultaneous treatment of HTM cells with TGF- $\beta 2$ and netarsudil abolished the induction of these markers by TGF- $\beta 2$, indicating an antifibrotic activity for netarsudil.

\section{Efficacy and tolerability in animal models}

Dose-dependent IOP-lowering and tolerability of netarsudil mesylate solutions were evaluated in normotensive Dutch Belted rabbits and Formosan Rock monkeys (Fig. 4). In both species, netarsudil formulations produced dose-dependent, statistically significant reductions in IOP at all time points as compared to the contralateral control eye $(P<0.05$, Student's paired $t$-test), with the maximum reduction being achieved after the third daily dose. In rabbits, the $0.005 \%, 0.01 \%, 0.02 \%$ and $0.04 \%$ solutions produced maximal IOP reductions on Day 3 of $2.5 \pm 0.2,4.6 \pm 0.2,5.0 \pm 0.6$, and $8.1 \pm 0.7 \mathrm{mmHg}$, respectively, at 4 or $8 \mathrm{~h}$ after dosing. All 4 solutions produced trace $(+0.5)$ to mild hyperemia $(+1)$ that typically persisted $4-8 \mathrm{~h}$ after dosing. No other adverse effects were noted. In monkeys, the $0.01 \%$, $0.02 \%$, and $0.04 \%$ solutions produced maximal IOP reductions of $4.2 \pm 0.2,5.8 \pm 0.3$, and $7.5 \pm 1.1 \mathrm{mmHg}$, respectively, at 4 or $8 \mathrm{~h}$ after dosing on Day 3. The IOP-lowering effect had a longer duration in monkeys compared to rabbits. As in rabbits, trace to mild hyperemia was the only adverse effect noted.

FIG. 2. Disruption of actin stress fibers and focal adhesions by netarsudil versus other ROCK inhibitors. (A) Netarsudil dose-response in actin stress fiber assay. Primary PTM cells were incubated for $6 \mathrm{~h}$ in the presence of $0,0.015,0.138$, or $1.2 \mu \mathrm{M}$ netarsudil then fixed and stained with Alexa Fluor-488 phalloidin and Hoechst 33342 to reveal actin fibers and nuclei, respectively. Top panel: fluorescence images of stained cells. Bottom panel: False color images created by an automated, custom algorithm to identify stress fibers and calculate mean stress fiber length. (B) Netarsudil dose-response in focal adhesion assay. Immortalized HTM cells (TM-1) were incubated for $6 \mathrm{~h}$ in the presence of $0,0.015,0.138$, or $1.2 \mu \mathrm{M}$ netarsudil then fixed and stained with mouse anti-paxillin antibody/Alexa Fluor ${ }^{\circledR} 488$ goat-anti-mouse IgG and Hoechst 33342 to reveal focal adhesions and nuclei, respectively. Top panel: fluorescence images of stained cells. Bottom panel: False color images created by an automated, custom algorithm to identify focal adhesions and calculate the mean number of focal adhesions per cell. (C) Dose-response curves $(n=4)$ for netarsudil, netarsudil-M1, AR-12286, Y-27632, and fasudil in the PTM actin stress fiber length assay. Mean stress fiber length is presented as a percentage of the mean length of stress fibers measured in untreated control cells. (D) Dose-response curves $(n=4)$ for netarsudil, netarsudil-M1, AR-12286, Y27632, and fasudil in the HTM focal adhesion assay. Mean number of focal adhesions per cell is presented as a percentage of the number of focal adhesions per cell measured in untreated control cells. HTM, human trabecular meshwork; PTM, porcine trabecular meshwork; ROCK, Rho-associated protein kinase. 
A

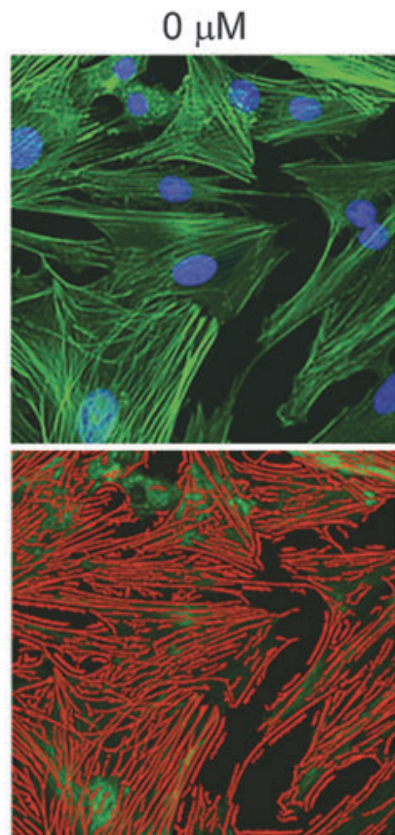

$0.015 \mu \mathrm{M}$

$0.138 \mu \mathrm{M}$

$1.2 \mu \mathrm{M}$
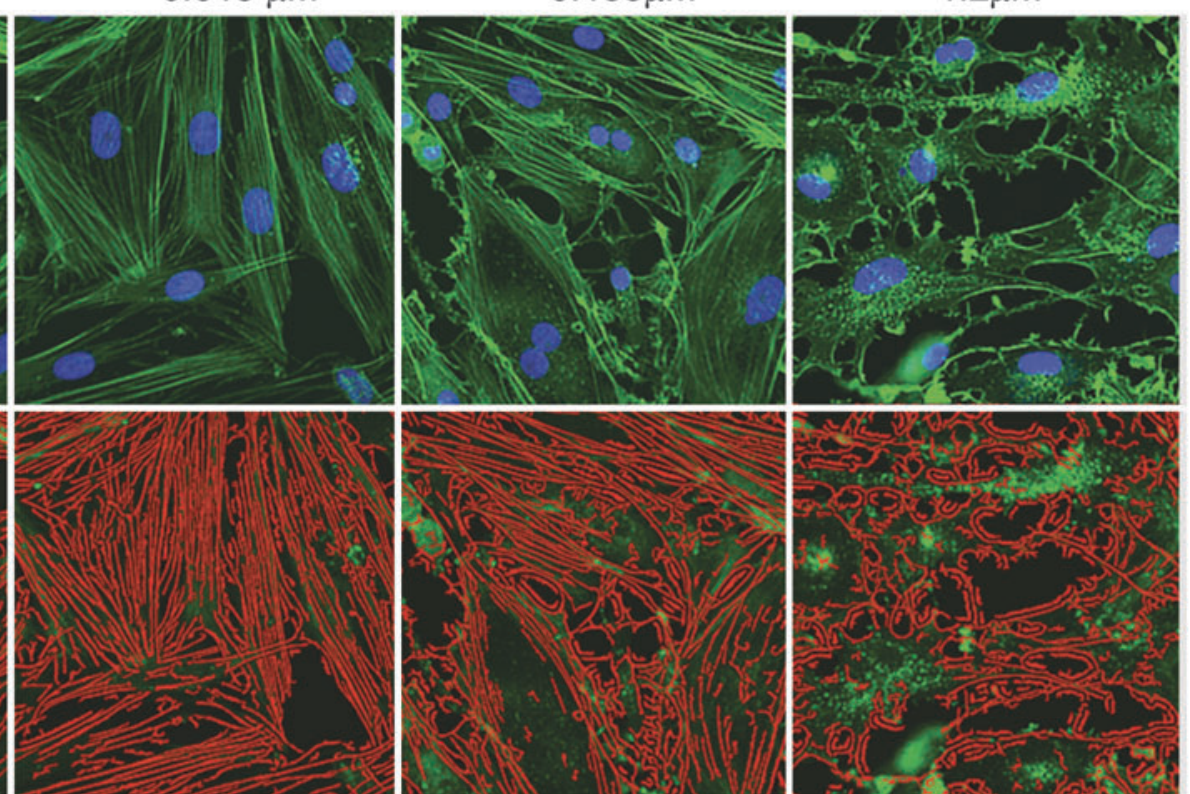

B

$0 \mu \mathrm{M}$

$0.015 \mu \mathrm{M}$

$0.138 \mu \mathrm{M}$

$1.2 \mu \mathrm{M}$
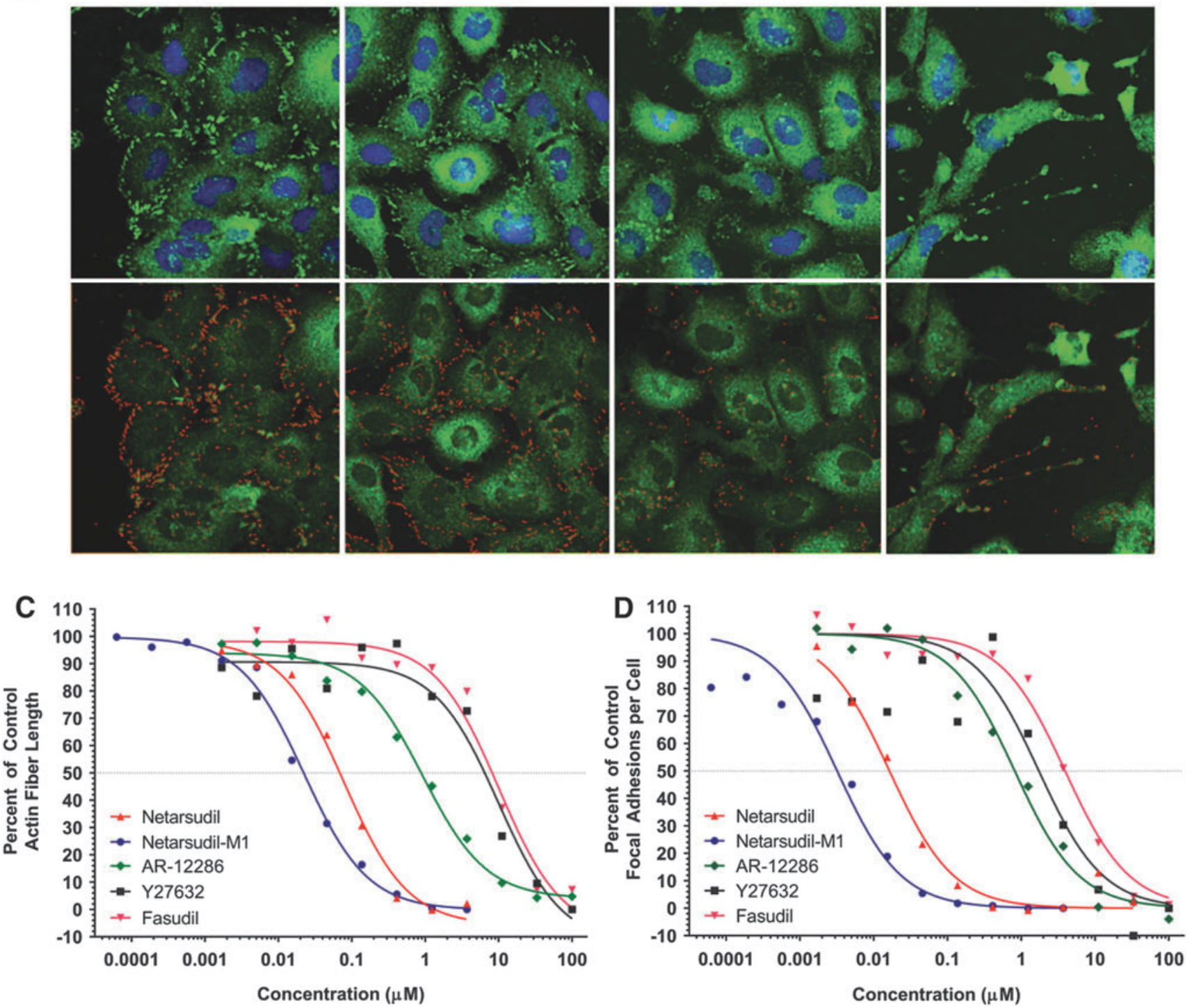


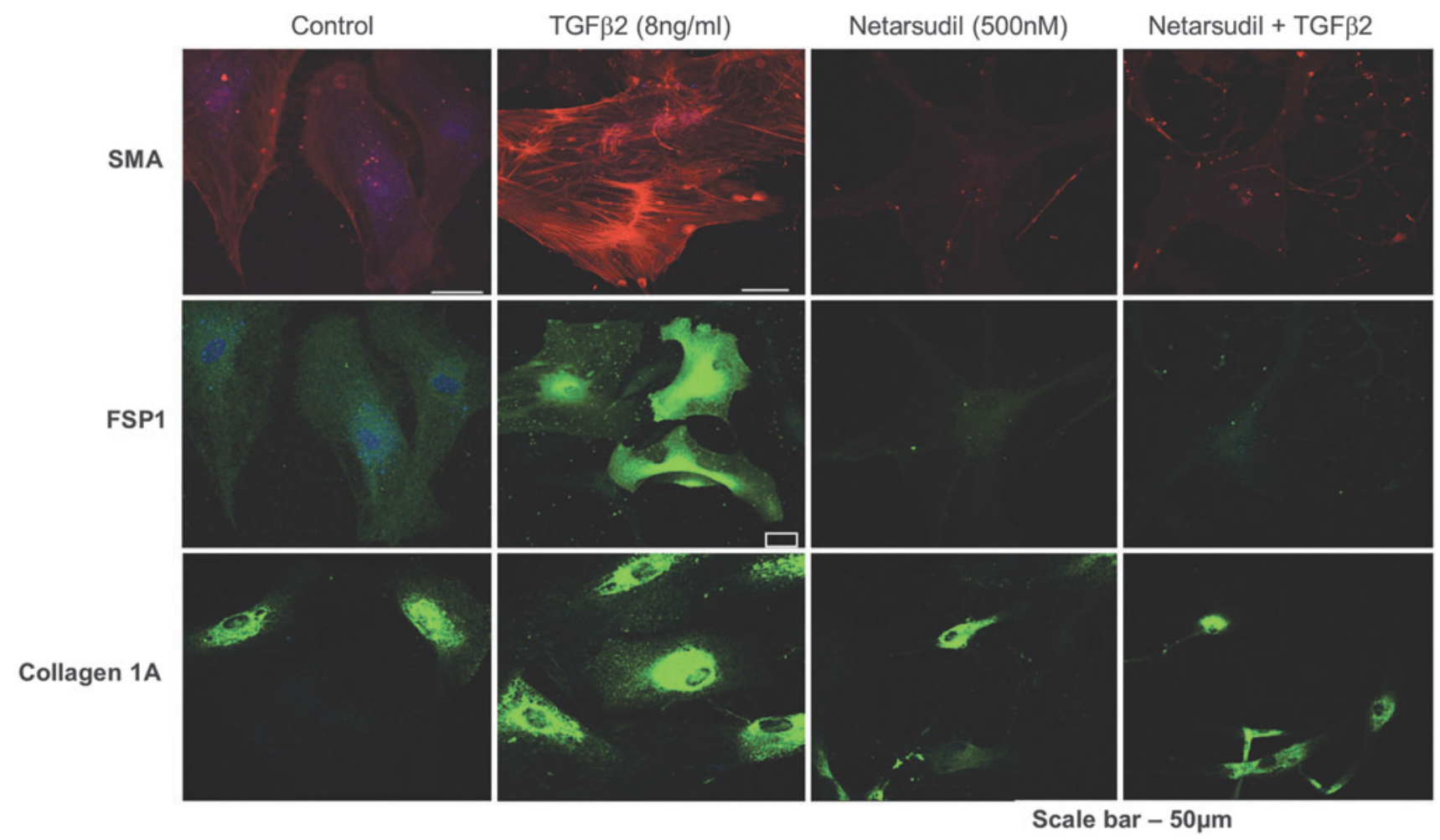

FIG. 3. Netarsudil blocks the profibrotic effects of TGF- $\beta$ on HTM cells. Serum-starved primary HTM cells incubated for $24 \mathrm{~h}$ in the presence of either vehicle, $8 \mathrm{ng} / \mathrm{mL}$ human TGF- $\beta 2,500 \mathrm{nM}$ netarsudil, or $8 \mathrm{ng} / \mathrm{mL}$ TGF- $\beta 2$ plus $500 \mathrm{nM}$ netarsudil were fixed and stained for the fibrogenic markers $\alpha$-SMA, fibroblast-specific protein 1 (FSP1), and Collagen 1A. $\alpha$-SMA, $\alpha$-smooth muscle actin; HTM, human trabecular meshwork; TGF- $\beta 2$, transforming growth factor- $\beta 2$.

The IOP-lowering effect of netarsudil $0.04 \%$ compared to AR-12286 $0.5 \%$ in normotensive Dutch Belted rabbits is presented in Fig. 5A. Netarsudil $0.04 \%$ achieved larger IOP reductions and a longer duration of effect. The difference was greatest at $8 \mathrm{~h}$ after dosing on Day 3, when netarsudil $0.04 \%$ produced an IOP reduction of $8.1 \pm 0.7 \mathrm{mmHg}$ compared to an IOP reduction of $2.9 \pm 0.2 \mathrm{mmHg}$ for $\mathrm{AR}-122860.5 \%$.

The IOP-lowering efficacy of netarsudil $0.04 \%$ was further compared to AR-12286 0.5\% in normotensive Formosan Rock monkeys (Fig. 5B). Netarsudil $0.04 \%$ and AR-12286 $0.5 \%$ produced similar IOP reductions on Day 1. By Day 3, netarsudil $0.04 \%$ demonstrated larger IOP reductions and a longer duration of effect than AR-12286 $0.5 \%$, with netarsudil $0.04 \%$ reducing IOP by $7.5 \pm 0.7$ and $7.5 \pm 1.1 \mathrm{mmHg}$ at 4 and $24 \mathrm{~h}$ after dosing, and AR-12286 $0.5 \%$ reducing IOP by $5.6 \pm 0.3$ and $3.9 \pm 0.3 \mathrm{mmHg}$ at 4 and $24 \mathrm{~h}$ after dosing.

\section{Pharmacokinetics}

Corneal metabolism of netarsudil was evaluated by incubating netarsudil in vitro with corneal tissue punches from rabbit, pig, dog, monkey, and human corneas (Fig. 6A). Metabolism of netarsudil by corneal tissue was evident for all species, with metabolism most rapid for $\operatorname{dog}\left(t_{1 / 2}=98 \mathrm{~min}\right)$, followed by monkey $\left(t_{1 / 2}=109 \mathrm{~min}\right)$, rabbit $\left(t_{1 / 2}=140 \mathrm{~min}\right)$, pig $\left(t_{1 / 2}=156 \mathrm{~min}\right)$, and human $\left(t_{1 / 2}=175 \mathrm{~min}\right)$ corneal tissues.

Ocular metabolism of netarsudil in rabbits was evaluated by measuring levels of netarsudil and netarsudil-M1 in $\mathrm{AH}$ samples following topical ocular dosing (Fig. 6B). Netarsudil-M1 was detected in all AH samples, whereas netarsudil concentrations were below the limit of detection
$(0.1 \mathrm{ng} / \mathrm{mL})$ in all but 1 of the 24 samples (Day $1,4 \mathrm{~h}$; $1.82 \mathrm{ng} / \mathrm{mL})$. The mean concentration of netarsudil-M1 in $\mathrm{AH}$ was $7.5 \pm 4.87$ and $3.95 \pm 2.53 \mathrm{ng} / \mathrm{mL}$ at 4 and $6 \mathrm{~h}$ postdose on Day 1, and 6.44 \pm 4.15 and $10.74 \pm 4.88 \mathrm{ng} / \mathrm{mL}$ at $4 \mathrm{~h}$ after the third and fourth daily dose, respectively.

The ocular and systemic bioavailability and distribution of ${ }^{14} \mathrm{C}$-netarsudil and ${ }^{3} \mathrm{H}$-AR-12286 was evaluated following a single topical ocular dose of netarsudil $0.02 \%$ or AR-12286 $0.5 \%$, respectively, to Dutch Belted rabbits (Table 2). In general, the rank order of maximum ${ }^{14} \mathrm{C}$-netarsudil radioactivity levels $\left(C_{\max }\right)$ was as follows: Cornea $>$ Conjunctiva $>>$ Iris/ciliary body $>>$ Retina-choroid-plexus $>A H>$ Vitreous humor $>$ Lens. A similar rank order of tissue exposure was obtained when measured as area under the curve over $48 \mathrm{~h}\left(\mathrm{AUC}_{0-48 \mathrm{~h}}\right)$. The distribution of ${ }^{3} \mathrm{H}-\mathrm{AR}-12286$ to ocular tissues differed somewhat from ${ }^{14} \mathrm{C}$ netarsudil, with a relatively higher exposure in the iris/ciliary body compared to other ocular tissues. The rank order of ${ }^{3} \mathrm{H}-\mathrm{AR}-$ $12286 C_{\max }$ values was as follows: Cornea $>$ Iris/ciliary body $>$ Conjunctiva $>$ Retina-choroid-plexus $>\mathrm{AH}>>$ Lens $>$ Vitreous humor. When tissue exposure was measured as $\mathrm{AUC}_{0-48 \mathrm{~h}}$, the highest tissue exposure to ${ }^{3} \mathrm{H}-\mathrm{AR}-12286$ was in the iris-ciliary body. The time required after dosing to reach peak tissue concentrations $\left(T_{\max }\right)$ was similar for ${ }^{14} \mathrm{C}$-netarsudil and ${ }^{3} \mathrm{H}-\mathrm{AR}$ 12286 in all tissues except $\mathrm{AH}$, for which $T_{\max }$ was $8 \mathrm{~h}$ for ${ }^{14} \mathrm{C}$ netarsudil compared to 0.25 to $0.5 \mathrm{~h}$ for ${ }^{3} \mathrm{H}-\mathrm{AR}-12286$.

The $C_{\max }$ values for netarsudil in $\mathrm{AH}$ were $\sim 30$-fold lower than for AR-12286, consistent with the 25-fold lower drug concentration in the netarsudil dosing solution. However, the $\mathrm{AUC}_{0-48 \mathrm{~h}}$ values for netarsudil were only $\sim 5$-fold lower than for AR-12286. This correlated with a longer terminal elimination half-life $\left(T_{1 / 2, \mathrm{e}}\right)$ in $\mathrm{AH}$ for netarsudil 
A

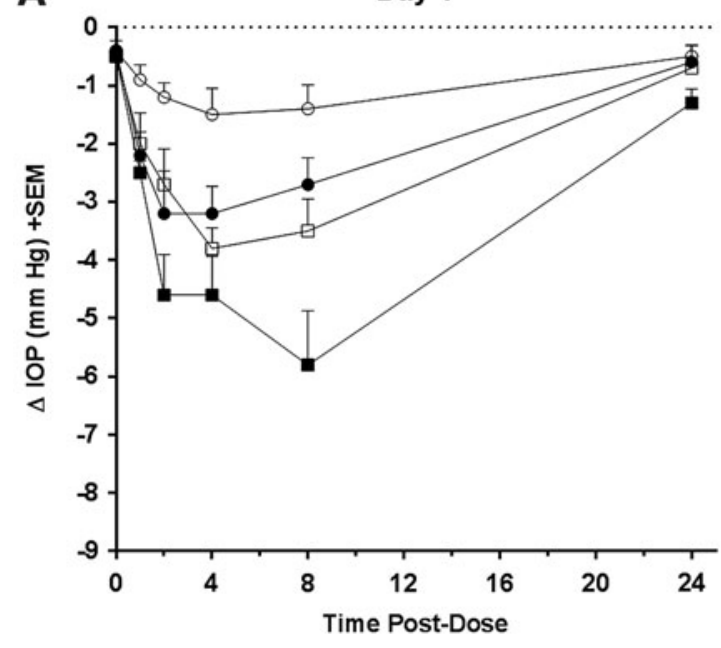

Day 1

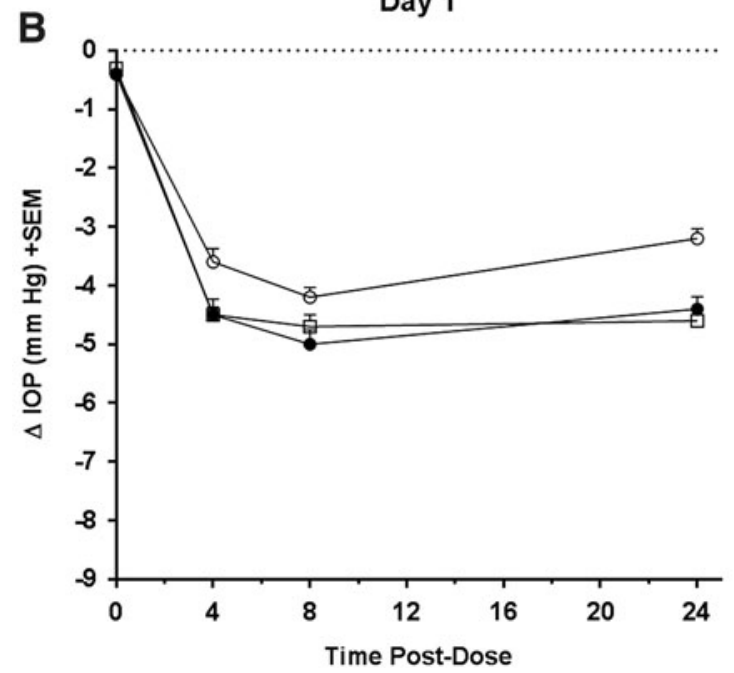

Day 3

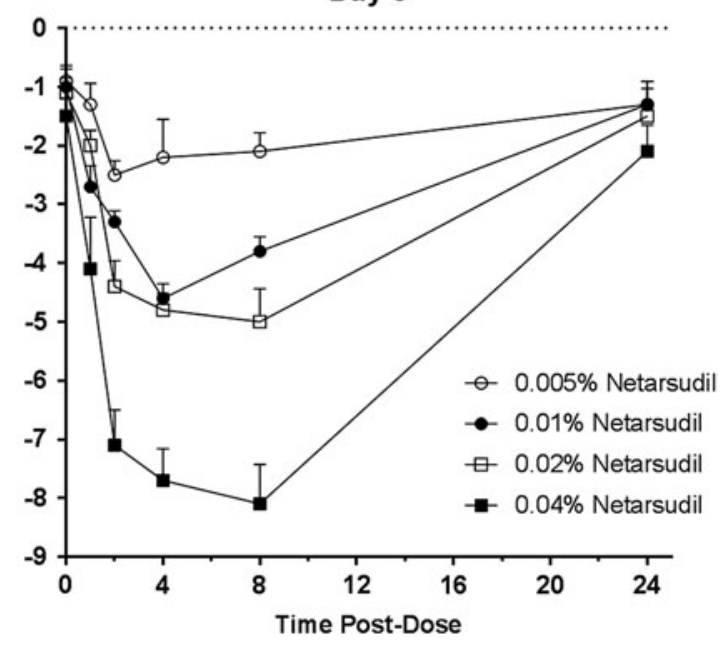

Day 3

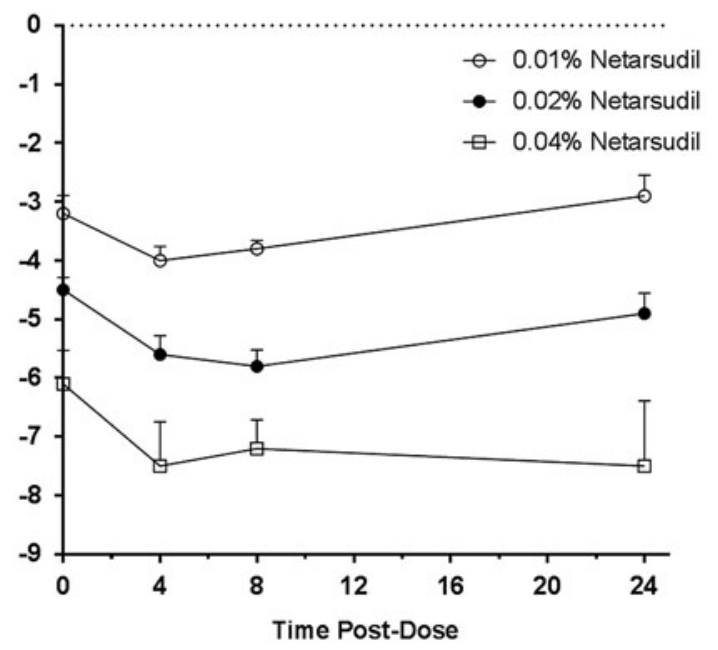

FIG. 4. Netarsudil dose-dependent lowering of IOP in rabbits and monkeys. Formulations containing $0.005 \%$ (rabbit only), $0.01 \%, 0.02 \%$, or $0.04 \%$ netarsudil were administered once daily (AM) to 1 eye of each animal for 3 days, with the fellow untreated eye serving as the control. IOP was determined for both eyes before test article administration (time 0 ) and at times 1, 2, 4, 8, and $24 \mathrm{~h}$ (rabbits) or 4, 8, and $24 \mathrm{~h}$ (monkeys) after each morning dose on Day 1 and 3. (A) Changes in IOP for the treated eye relative to the untreated contralateral eye in Dutch Belted rabbits $(n=10 /$ group). IOP reductions were statistically significant $(P<0.05)$ at all postdose time points. (B) Change in IOP in the netarsudil-treated eye relative to the untreated contralateral eye in Formosan Rock monkeys ( $n=6$ /group). IOP reductions were statistically significant $(P<0.05)$ at all postdose time points. IOP, intraocular pressure.

(16-17 h) compared to AR-12286 (9-11 h). The $T_{1 / 2, \mathrm{e}}$ values for netarsudil in cornea, conjunctiva, and vitreous humor, in addition to blood, plasma, liver, and kidney, ranged from 12 to $27 \mathrm{~h}$. Elimination of netarsudil from retina-choroid-plexus, lens, and iris/ciliary body was much slower, with $T_{1 / 2, \mathrm{e}}$ values ranging from 68 to $112 \mathrm{~h}$. For AR-12286, $T_{1 / 2, \mathrm{e}}$ values were similar across all tissues measured and ranged from 9 to $41 \mathrm{~h}$.

As expected for topical ocular dosing, maximum systemic concentrations of ${ }^{14} \mathrm{C}$-netarsudil in blood, plasma, liver, and kidney were $\sim 200$ - to 3000 -fold lower than in the cornea and conjunctiva.

\section{Discussion}

The preclinical pharmacology and pharmacokinetics studies presented herein demonstrate that netarsudil is a potent
ROCK inhibitor that disrupts actin stress fibers and focal adhesions in TM cells, blocks the profibrotic effects of TGF$\beta 2$, and produces large reductions in IOP that are sustained for at least $24 \mathrm{~h}$ after once daily dosing. Topical application of netarsudil was well tolerated, with only transient, mild hyperemia observed as an adverse effect. Based on its promising preclinical efficacy and safety profile, netarsudil was selected as a lead candidate for clinical development.

Biochemical assays revealed netarsudil to be highly effective at inhibiting ROCK1 and ROCK2, with a potency that is $>20$-fold greater than the most commonly studied ROCK inhibitors, Y-27632 and fasudil. Furthermore, netarsudil-M1, the esterase metabolite of netarsudil, was found to have 5-fold greater potency than netarsudil itself, with a $K_{\mathrm{i}}$ of $0.2 \mathrm{nM}$ for each ROCK isoform. These results identify netarsudil-M1 as one of the most potent ROCK inhibitors described to date. 

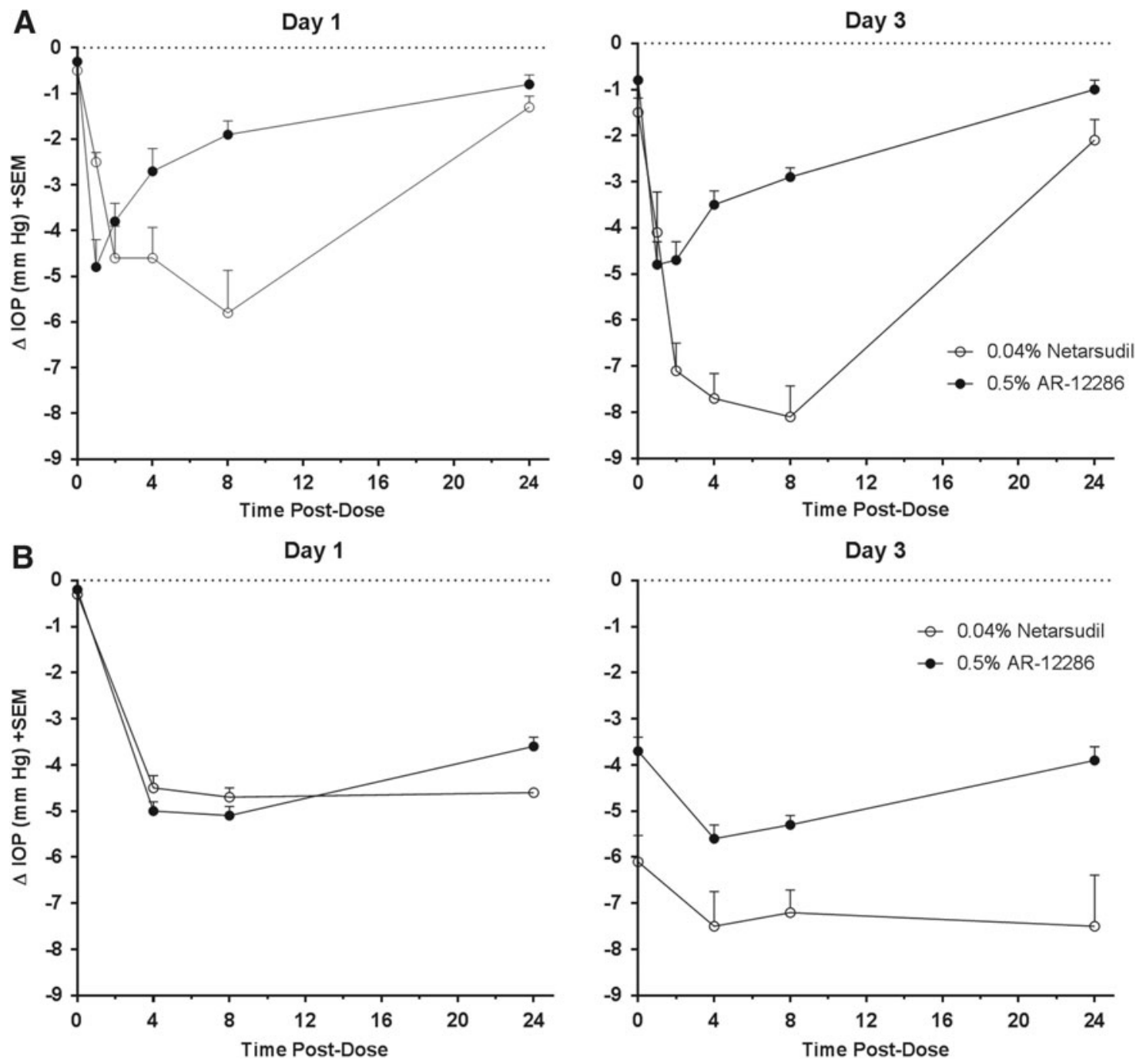

Day 3

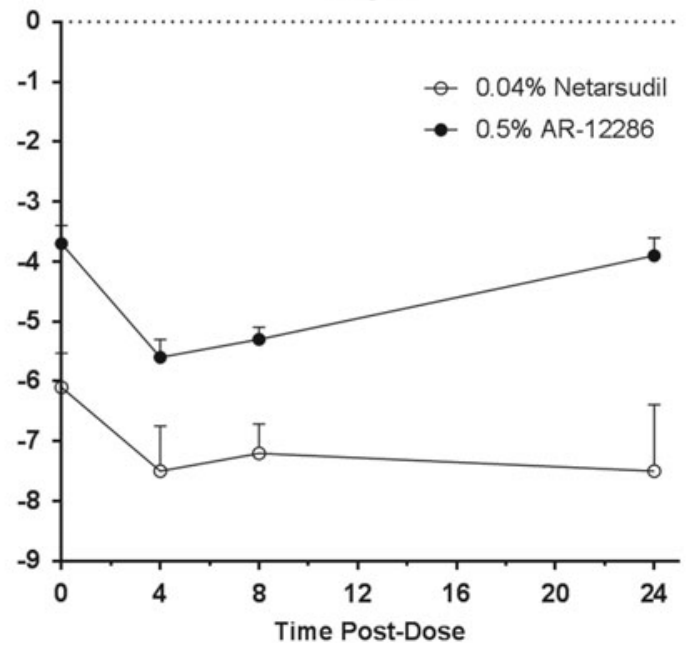

FIG. 5. IOP-lowering effect of netarsudil versus AR-12286 in rabbits and monkeys. Netarsudil $0.04 \%$ or AR-12286 $0.5 \%$ was administered once daily (AM) to 1 eye of each animal for 3 days, with the fellow untreated eye serving as the control. IOP was determined for both eyes before test article administration (time 0 ) and at times 1, 2, 4, 8, and 24 h (rabbits) or 4, 8, and $24 \mathrm{~h}$ (monkeys) after each morning dose on Day 1 and 3. (A) Change in IOP in the treated eye relative to the untreated contralateral eye in Dutch Belted rabbits $(n=12$ /group). For netarsudil 0.04\% and AR-12286 0.5\%, IOP reductions were statistically significant $(P<0.01)$ at all postdose time points. $(\mathbf{B})$ Change in IOP in the treated eye relative to the untreated contralateral eye in Formosan Rock monkeys $(n=6 /$ group). For netarsudil $0.04 \%$ and AR-12286 0.5\%, IOP reductions were statistically significant $(P<0.01)$ at all postdose time points. IOP, intraocular pressure.

ROCK inhibitors relax the TM and increase the permeability of Schlemm's canal by blocking the formation of actin stress fibers and focal adhesions, which contribute to cell shape and stiffness. ${ }^{13}$ As expected, netarsudil and netarsudil-M1 were highly effective at disrupting actin stress fibers and focal adhesions in both porcine and human TM cells. Netarsudil-M1 was $\sim 5$-fold more potent than netarsudil in these cell-based assays, consistent with its greater ROCK inhibitory activity.

TGF- $\beta 2$ is a profibrotic cytokine that has been found at elevated levels in the $\mathrm{AH}$ of patients with open angle glaucoma. ${ }^{32}$ This cytokine is thought to play a major role in promoting increased extracellular matrix stiffness and cell contraction in the TM, thereby contributing to elevated IOP. ${ }^{33}$ Importantly, ROCK inhibitors have previously been shown to block the fibrogenic response of human TM cells to TGF- $\beta 2,{ }^{27}$ and to have antifibrotic activity in animal models of cardiac fibrosis, liver fibrosis, kidney fibrosis, and pulmonary fibrosis. ${ }^{34-36}$ Our results confirm that netarsudil shares the antifibrotic activity described for other ROCK inhibitors. These data suggest that netarsudil may have the potential to modify the fibrotic disease processes at the TM that are associated with elevated IOP.

A number of ophthalmic drugs have been developed as ester prodrugs as a means to reduce ocular side effects and increase corneal penetration. ${ }^{37-39}$ As these prodrugs pass through the cornea they are converted to the active form of the drug by corneal esterases. Netarsudil is similarly converted to a more potent drug, netarsudil-M1, as it passes through the cornea and into the $\mathrm{AH}$ following topical ocular dosing in rabbits. Conversion of netarsudil to netarsudil-M1 by corneal esterases may explain why netarsudil, which has only 2-fold greater potency for ROCK than AR-12286, achieved the same maximum IOP reduction as AR-12286 

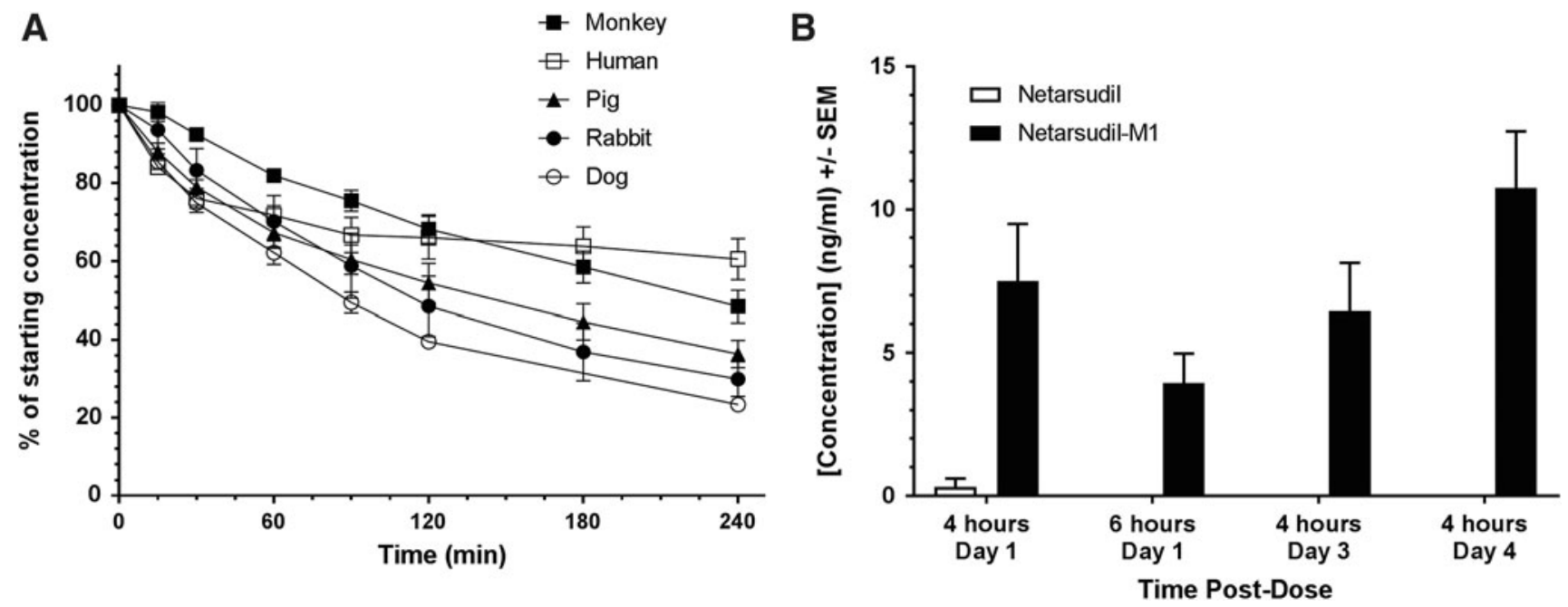

FIG. 6. Metabolism of netarsudil by ocular tissues. (A) Metabolism of netarsudil in the presence of corneal tissue isolated from Dutch Belted rabbit $(n=3)$, beagle dog $(n=3)$, pig $(n=3)$, cynomolgus monkey $(n=4)$, and human $(n=3)$ corneas. Corneal metabolism assays were initiated by adding netarsudil in assay buffer to wells containing individual corneal punches in assay buffer followed by incubation at $37^{\circ} \mathrm{C}$. Samples were removed at specified time intervals and analyzed by HPLC to determine the percentage of netarsudil remaining at each time point. (B) Levels of netarsudil versus netarsudil-M1 in $\mathrm{AH}$ following topical ocular application of netarsudil $0.02 \%$ to Dutch Belted rabbits. Netarsudil was administered to both eyes of 3 male New Zealand rabbits in each of 4 groups. In groups 1 and 2, test article was dosed only once, and samples of $\mathrm{AH}$ were taken from each eye by paracentesis at 4 or $6 \mathrm{~h}$ postdose, respectively. In groups 3 and 4 , test article was dosed once daily for 3 or 4 days, respectively, and samples of AH were taken $4 \mathrm{~h}$ after dosing. Levels of netarsudil and its metabolite netarsudil-M1 were measured in the samples by HPLC/mass spectrometry. AH, aqueous humor; HPLC, high performance liquid chromatography.

Table 2. Pharmacokinetic Parameters for ${ }^{14}$ C-Netarsudil and ${ }^{3}$ H-AR-12286 Following a Single Topical Ocular Dose in Dutch Belted Rabbits

\begin{tabular}{|c|c|c|c|c|c|c|c|c|c|}
\hline \multirow[b]{2}{*}{ Tissue } & \multirow[b]{2}{*}{ Eye } & \multicolumn{4}{|c|}{${ }^{14} \mathrm{C}$-Netarsudil $(0.02 \%)$} & \multicolumn{4}{|c|}{${ }^{3} H-A R-12286(0.5 \%)$} \\
\hline & & $\begin{array}{c}\mathrm{C}_{\max } \\
n g \cdot e q / g\end{array}$ & $\mathrm{~T}_{\max }, h$ & $\begin{array}{c}A U C_{\text {last }} \\
n g \cdot e q \cdot h / g\end{array}$ & $\mathrm{~T}_{1 / 2, e}, h$ & $\begin{array}{c}\mathrm{C}_{\max } \\
n g \cdot e q / g\end{array}$ & $\mathrm{~T}_{\max }, h$ & $\begin{array}{c}A U C_{\text {last }}, \\
n g \cdot e q \cdot h / g\end{array}$ & $\mathrm{~T}_{1 / 2, \mathrm{e}}, h$ \\
\hline Cornea & $\begin{array}{l}\mathrm{L} \\
\mathrm{R}\end{array}$ & $\begin{array}{l}3,666 \\
3,972\end{array}$ & $\begin{array}{l}0.5 \\
0.25\end{array}$ & $\begin{array}{l}63,387 \\
69,605\end{array}$ & $\begin{array}{l}14 \\
13\end{array}$ & $\begin{array}{l}10,309 \\
10,691\end{array}$ & $\begin{array}{l}0.25 \\
0.25\end{array}$ & $\begin{array}{l}54,433 \\
93,347\end{array}$ & $\begin{array}{l}21 \\
13\end{array}$ \\
\hline Conjuctiva & $\begin{array}{l}\mathrm{L} \\
\mathrm{R}\end{array}$ & $\begin{array}{l}2,442 \\
3,292\end{array}$ & $\begin{array}{l}0.25 \\
0.25\end{array}$ & $\begin{array}{r}9,525 \\
12,390\end{array}$ & $\begin{array}{l}13 \\
17\end{array}$ & $\begin{array}{l}5,374 \\
4,071\end{array}$ & $\begin{array}{l}0.25 \\
0.5\end{array}$ & $\begin{array}{l}34,248 \\
77,672\end{array}$ & $\begin{array}{l}37 \\
34\end{array}$ \\
\hline Iris-ciliary body & $\begin{array}{l}\mathrm{L} \\
\mathrm{R}\end{array}$ & $\begin{array}{l}955 \\
416\end{array}$ & $\begin{array}{l}0.25 \\
8\end{array}$ & $\begin{array}{l}10,845 \\
11,555\end{array}$ & $\begin{array}{l}\text { n.d. } \\
112\end{array}$ & $\begin{array}{l}8,394 \\
6,373\end{array}$ & $\begin{array}{l}1 \\
1\end{array}$ & $\begin{array}{l}170,278 \\
150,748\end{array}$ & $\begin{array}{l}36 \\
41\end{array}$ \\
\hline Retina-choroid-plexus & $\begin{array}{l}\mathrm{L} \\
\mathrm{R}\end{array}$ & $\begin{array}{l}80 \\
50\end{array}$ & $\begin{array}{l}0.25 \\
0.5\end{array}$ & $\begin{array}{l}1,390 \\
1,298\end{array}$ & $\begin{array}{r}204 \\
68\end{array}$ & $\begin{array}{l}1,074 \\
1,379\end{array}$ & $\begin{array}{l}0.25 \\
1\end{array}$ & $\begin{array}{l}15,117 \\
19,130\end{array}$ & $\begin{array}{l}26 \\
30\end{array}$ \\
\hline Aqueous humor & $\begin{array}{l}\mathrm{L} \\
\mathrm{R}\end{array}$ & $\begin{array}{l}16 \\
23\end{array}$ & $\begin{array}{l}8 \\
8\end{array}$ & $\begin{array}{l}510 \\
613\end{array}$ & $\begin{array}{l}17 \\
16\end{array}$ & $\begin{array}{l}595 \\
734\end{array}$ & $\begin{array}{l}0.25 \\
0.5\end{array}$ & $\begin{array}{l}2,648 \\
3,205\end{array}$ & $\begin{array}{r}11 \\
9\end{array}$ \\
\hline Vitreous humor & $\begin{array}{l}\mathrm{L} \\
\mathrm{R}\end{array}$ & $\begin{array}{l}7 \\
4\end{array}$ & $\begin{array}{l}0.25 \\
0.25\end{array}$ & $\begin{array}{l}51 \\
51\end{array}$ & $\begin{array}{l}12 \\
15\end{array}$ & $\begin{array}{l}35 \\
33\end{array}$ & $\begin{array}{l}0.5 \\
0.5\end{array}$ & $\begin{array}{l}484 \\
420\end{array}$ & $\begin{array}{l}10 \\
38\end{array}$ \\
\hline Lens & $\begin{array}{l}\mathrm{L} \\
\mathrm{R}\end{array}$ & $\begin{array}{l}2 \\
2\end{array}$ & $\begin{array}{l}0.25 \\
0.25\end{array}$ & $\begin{array}{l}33 \\
37\end{array}$ & $\begin{array}{l}99 \\
83\end{array}$ & $\begin{array}{l}59 \\
55\end{array}$ & $\begin{array}{l}0.25 \\
1\end{array}$ & $\begin{array}{r}937 \\
1,383\end{array}$ & $\begin{array}{l}36 \\
19\end{array}$ \\
\hline Blood & $\mathrm{n} / \mathrm{a}$ & 1 & 0.25 & 15 & 27 & 40 & 0.5 & 317 & 27 \\
\hline Plasma & $\mathrm{n} / \mathrm{a}$ & 1 & 0.5 & 24 & 16 & 40 & 0.5 & 302 & 35 \\
\hline Liver & $\mathrm{n} / \mathrm{a}$ & 6 & 1 & 88 & 13 & 274 & 1 & 3,314 & 18 \\
\hline Kidney & $\mathrm{n} / \mathrm{a}$ & 19 & 1 & 298 & 16 & 355 & 0.5 & 2,549 & 15 \\
\hline
\end{tabular}

$\mathrm{AUC}_{\text {last }}$, area under the curve; $C_{\max }$, maximum observed concentration of radioactivity; $T_{\max }$, time of maximum radioactivity concentration; $T_{1 / 2, \mathrm{e}}$, apparent elimination half-life of radioactivity. 
even when dosed at a 25 -fold lower concentration in normotensive rabbits $(0.02 \%$ vs. $0.5 \%$, respectively). The disproportionately high effectiveness of netarsudil does not appear to be due to a difference in ocular bioavailability, since the maximum concentration of netarsudil- and AR-12286-related radioactivity in rabbit $\mathrm{AH}$ was proportional to their respective dosing concentrations $(0.02 \%$ and $0.5 \%$, respectively). This suggests that the enhanced IOP-lowering efficacy of netarsudil relative to AR-12286 is a result of the more potent netarsudil-M1 being the predominant form of netarsudil in $\mathrm{AH}$ following topical ocular dosing in rabbits.

Factors other than ROCK potency may also contribute to the greater IOP-lowering effectiveness of netarsudil compared to AR-12286. Peak efficacy for AR-12286 occurred at $0.5 \mathrm{~h}$ after dosing on Day 1 , and by $8 \mathrm{~h}$ more than half of the AR-12286 IOP-lowering effect was lost. In contrast, netarsudil did not reach its peak efficacy until $8 \mathrm{~h}$ after dosing. This longer duration of IOP reduction for netarsudil versus AR-12286 was consistent with their respective ocular pharmacokinetic profiles. AR-12286 dosing produced a maximum $\mathrm{AH}$ drug concentration at 0.25 to $0.5 \mathrm{~h}$ after dosing, whereas netarsudil dosing produced a maximum $\mathrm{AH}$ drug concentration at $8 \mathrm{~h}$ after dosing. In addition, the $\mathrm{AH}$ half-life for netarsudil-related radioactivity was $\sim 60 \%$ longer than that for AR-12286.

The greater efficacy and longer duration of IOP lowering for netarsudil in rabbits could also be related to its NET inhibitory activity. Inhibition of NET blocks reuptake of norepinephrine at noradrenergic synapses and thereby increases the strength and duration of endogenous norepinephrine signaling. ${ }^{40}$ Topical application of norepinephrine has been shown to cause a delayed and prolonged IOP reduction in rabbits. ${ }^{41,42}$ The mechanism may involve reduced AH formation due to norepinephrine-induced vasoconstriction, which may cause reduced blood flow to the ciliary processes. $^{41}$ It is therefore of interest that netarsudil was shown to reduce $\mathrm{AH}$ formation following topical ocular dosing in monkeys. ${ }^{20}$ However, while netarsudil possesses NET inhibitory activity, netarsudil-M1 does not inhibit NET (data not shown). The contribution of NET inhibition to the IOP-lowering effect of netarsudil requires further study.

The diurnal pattern of IOP reduction in normotensive monkeys differed significantly from normotensive rabbits. In monkeys, netarsudil $0.04 \%$ maintained its full IOPlowering effect for $24 \mathrm{~h}$ after dosing, whereas in rabbits much of the IOP-lowering effect was lost by $24 \mathrm{~h}$. AR$122860.5 \%$ also had a much longer duration of effect in monkeys than in rabbits. In addition, netarsudil $0.04 \%$ and AR-12286 $0.5 \%$ produced similar IOP reductions in monkeys on Day 1. By Day 3, netarsudil $0.04 \%$ achieved larger IOP reductions than AR-12286 0.5\%, but the difference in diurnal efficacy between the 2 drugs was much greater in rabbits than in monkeys. Given that the physiology of the monkey trabecular outflow pathway is more similar to humans than is the rabbit outflow pathway, ${ }^{43}$ the monkey would be expected to be the better model for evaluating the relative efficacy of trabecular outflow drugs. This assumption is supported by the results of Phase 1 clinical trials conducted in normotensive volunteers with netarsudil ${ }^{44}$ and AR-12286. ${ }^{45}$ In these studies, the diurnal pattern of IOP reduction for each drug was similar to the results obtained in normotensive monkeys.
The ability to maintain IOP-lowering efficacy for $24 \mathrm{~h}$ after dosing was a key criterion that netarsudil needed to meet for advancement into clinical trials. ROCK inhibition is known to cause relaxation of vascular smooth muscle. ${ }^{46}$ Due to this activity, application of a ROCK inhibitor to the eye causes vasodilation of conjunctival blood vessels, which can produce conjunctival hyperemia, or "red eyes." In our animal testing of netarsudil, conjunctival hyperemia was trace to mild in severity and short-lived. This suggested that if patients could dose netarsudil once daily in the evening, the hyperemia would likely resolve during the night and not be noticeable during the day. This strategy for minimizing hyperemia proved effective in a 28-day clinical study of netarsudil $0.02 \%$ dosed once daily in the evening, with $65 \%$ to $76 \%$ of patients scored as having no hyperemia or trace hyperemia at the Day 7 and 28 morning visits. ${ }^{24}$

The effect of netarsudil on trabecular outflow facility has been studied in enucleated mouse and human eyes and in living monkeys. In mouse eyes perfused with netarsudil-M1 for $\sim 1 \mathrm{~h}$, outflow facility increased by $56 \%$ for C57 mice and $91 \%$ for CD1 mice. ${ }^{21}$ In human donor eyes perfused with netarsudil-M1 for $3 \mathrm{~h}$, outflow facility increased by $59.7 \%$ relative to control eyes. ${ }^{23}$ A similar increase in outflow facility was measured in live monkeys $6 \mathrm{~h}$ after topical dosing with netarsudil $0.04 \%$, which produced a $53 \%$ increase in tonographic outflow facility. ${ }^{20}$ In the current study, the IOP-lowering effect of netarsudil $0.04 \%$ in monkeys was notably greater on Day 3 of dosing as compared to Day 1. This suggests that the acute dosing studies might not have captured the maximal effect of netarsudil on outflow facility. Given that netarsudil also produced much larger reductions in IOP on Day 8 compared to Day 1 in a Phase 1 clinical trial, ${ }^{44}$ evaluation of netarsudil's effects on AH dynamics in humans should incorporate several days of dosing.

In summary, netarsudil is a novel ROCK/NET inhibitor selected for clinical development based upon its high potency in biochemical and cell-based assays, its ability to produce large and durable IOP reductions in animal models, and its favorable pharmacokinetic and ocular tolerability profiles. Based upon the successful completion of Phase 2 clinical studies in patients with glaucoma or ocular hypertension, netarsudil has been advanced to Phase 3 clinical trials. If approved for use, netarsudil will provide a new treatment option for lowering IOP that targets the diseased trabecular outflow pathway.

\section{Acknowledgment}

The authors thank Briana Foley for her expert assistance in providing high quality images of cell-based assay results for this publication.

\section{Author Disclosure Statement}

C.-W.L., B.S., L.A.M., C.L.L., M.A.d.L., and C.C.K. are employees of and stockholders in Aerie Pharmaceuticals, Inc. D.-W.L. and P.V.R. received research funding from Aerie Pharmaceuticals.

\section{References}

1. Alward, W.L. Medical management of glaucoma. N. Engl. J. Med. 339:1298-1307, 1998. 
2. Casson, R.J., Chidlow, G., Wood, J.P.M., et al. Definition of glaucoma: clinical and experimental concepts. Clin. Exp. Ophthalmol. 40:341-349, 2012.

3. Vrabec, J.P., and Levin, L.A. The neurobiology of cell death in glaucoma. Eye. 21:S11-S14, 2007.

4. Schwartz, K., and Budenz, D. Current management of glaucoma. Curr. Opin. Ophthalmol. 15:119-126, 2004.

5. Stamer, W.D., and Acott, T.S. Current understanding of conventional outflow dysfunction in glaucoma. Curr. Opin. Ophthalmol. 23:135-143, 2012.

6. Grant, W.M. Clinical tonography. Trans. Am. Acad. Ophthalmol. Otolaryngol. 55:774-781, 1951.

7. Bucolo, C., Platania, C.B., Reibaldi, M., Bonfiglio, V., Longo, A., Salomone, S., and Drago, F. Controversies in glaucoma: current medical treatment and drug development. Curr. Pharm. Des. 21:4673-4681, 2015.

8. Bucolo, C., Salomone, S., Drago, F., Reibaldi, M., Longo, A., and Uva, M.G. Pharmacological management of ocular hypertension: current approaches and future prospective. Curr. Opin. Pharmacol. 13:50-55, 2013.

9. Flocks, M., and Zweng, H.C. Studies on the mode of action of pilocarpine on aqueous outflow. Am. J. Ophthalmol. 44:380-386, 1957.

10. Barany, E.H. The mode of action of pilocarpine on outflow resistance in the eye of a primate (Cercopithecus ethiops). Invest. Ophthalmol. 1:712-727, 1962.

11. Donegan, R.K., and Lieberman, R.L. Discovery of molecular therapeutics for glaucoma: challenges, successes, and promising directions. J. Med. Chem. 59:788-809, 2016.

12. Rao, P.V., Pattabiraman, P.P., and Kopczynski, C. Role of the Rho GTPase/Rho kinase signaling pathway in pathogenesis and treatment of glaucoma: bench to bedside research. Exp. Eye. Res. 2016. pii: S0014-483530240-8.

13. Wang, S.K., and Chang, R.T. An emerging treatment option for glaucoma: Rho kinase inhibitors. Clin. Ophthalmol. 8:883-890, 2014.

14. Honjo, M., Tanihara, H., Inatani, M., et al. Effects of rhoassociated protein kinase inhibitor Y-27632 on intraocular pressure and outflow facility. Invest. Ophthalmol. Vis. Sci. 42:137-144, 2001.

15. Thieme, H., Nuskovski, M., Nass, J.U., et al. Mediation of calcium-independent contraction in trabecular meshwork through protein kinase $\mathrm{C}$ and rhoA. Invest. Ophthalmol. Vis. Sci. 41:4240-4246, 2000.

16. Rao, P.V., Deng, P.F., Kumar, J., et al. Modulation of aqueous humor outflow facility by the Rho kinase-specific inhibitor Y-27632. Invest. Ophthalmol. Vis. Sci. 42:10291037, 2011.

17. Kopczynski, C.C., and Epstein, D.L. Emerging trabecular outflow drugs. J. Ocul. Pharmacol. Ther. 30:85-87, 2014.

18. Garnock-Jones, K.P. Ripasudil: first global approval. Drugs. 74:2211-2215, 2014.

19. Sturdivant, J.M., Royalty, S.M., Lin, C.W., et al. Discovery of the ROCK inhibitor netarsudil for the treatment of openangle glaucoma. Bioorg. Med. Chem. Lett. 26:2475-2480, 2016.

20. Wang, R.F., Williamson, J.E., Kopczynski, C., et al. Effect of $0.04 \%$ AR-13324, a ROCK, and norepinephrine transporter inhibitor, on aqueous humor dynamics in normotensive monkey eyes. J. Glaucoma. 24:51-54, 2015.

21. Li, G., Mukherjee, D., Navarro, I., et al. Visualization of conventional outflow tissue responses to netarsudil in living mouse eyes. Eur. J. Pharmacol. 787:20-31, 2016.
22. Kiel, J.W., and Kopczynski, C. Effect of netarsudil on episcleral venous pressure in Dutch Belted rabbits. J. Ocul. Pharmacol. Ther. 31:146-151, 2015.

23. Ren, R., Li, G., Le, T.D., et al. Netarsudil increases outflow facility in human eyes through multiple mechanisms. Invest. Ophthalmol. Vis. Sci. 57:6197-6209, 2016.

24. Bacharach, J., Dubiner, H.B., Levy, B., et al.; AR-13324CS202 Study Group. Double-masked, randomized, doseresponse study of AR-13324 versus latanoprost in patients with elevated intraocular pressure. Ophthalmology. 122: 302-307, 2015.

25. Lewis, R.A., Levy, B., Ramirez, N., et al.; PG324-CS201 Study Group. Fixed-dose combination of AR-13324 and latanoprost: a double-masked, 28-day, randomised, controlled study in patients with open-angle glaucoma or ocular hypertension. Br. J. Ophthalmol. 100:339-344, 2016.

26. Katz, J.L., Weiss, M.J., Heah, T., et al. Two Phase 3 studies of the efficacy and safety of AR-13324 Ophthalmic Solution 0.02\%: in Patients with Open Angle Glaucoma and Ocular Hypertension. Invest. Ophthalmol. Vis. Sci. 57: 2016 [ARVO abstract].

27. Rao, P.V., and Epstein, D.L. Rho GTPase/Rho kinase inhibition as a novel target for the treatment of glaucoma. BioDrugs. 21:167-177, 2007.

28. Pattabiraman, P.P., Maddala, R., and Rao, P.V. Regulation of plasticity and fibrogenic activity of trabecular meshwork cells by Rho GTPase signaling. J. Cell. Physiol. 229:927942, 2014.

29. Pattabiraman, P.P., and Rao, P.V. Mechanistic basis of Rho GTPase-induced extracellular matrix synthesis in trabecular meshwork cells. Am. J. Physiol. Cell Physiol. 298:C749C763, 2010.

30. Draize, J.H., Woodard, G., and Calvery, H. J. Methods for the study of irritation and toxicity of substances applied topically to the skin and mucous membranes. Pharmacol. Exp. Ther. 82:377-390, 1944.

31. Yau, C.W., and Kaufman, H.E. A medium-term corneal preserving medium (K-Sol). Arch. Ophthalmol. 104:598601, 1986.

32. Tripathi, R.C., Li, J., Chan, W.F., et al. Aqueous humor in glaucomatous eyes contains an increased level of TGF-beta 2. Exp. Eye Res. 59:723-727, 1994.

33. Fuchshofer, R. The pathogenic role of transforming growth factor- $\beta 2$ in glaucomatous damage to the optic nerve head. Exp. Eye Res. 93:165-169, 2011.

34. Knipe, R.S., Tager, A.M., and Liao, J.K. The Rho kinases: critical mediators of multiple profibrotic processes and rational targets for new therapies for pulmonary fibrosis. Pharmacol. Rev. 67:103-117, 2015.

35. Moriyama, T., and Nagatoya, K. The Rho-ROCK system as a new therapeutic target for preventing interstitial fibrosis. Drug News Perspect. 17:29-34, 2014.

36. Tsou, P.S., Haak, A.J., Khanna, D., and Neubig, R.R. Cellular mechanisms of tissue fibrosis. 8. Current and future drug targets in fibrosis: focus on Rho GTPaseregulated gene transcription. Am. J. Physiol. Cell. Physiol. 307:C2-C13, 2014.

37. Chang, S.C., and Lee, V.H. Influence of chain length on the in vitro hydrolysis of model ester prodrugs by ocular esterases. Curr. Eye Res. 2:651-656, 19821983.

38. Gherezghiher, T., and Koss, M.C. Ocular effects of dipivalyl esters of epinephrine and alpha-methylepinephrine. Exp. Eye Res. 51:537-543, 1990. 
39. Rácz, P., Ruzsonyi, M.R., Nagy, Z.T., et al. Maintained intraocular pressure reduction with once-a-day application of a new prostaglandin F2 alpha analogue (PhXA41). An in-hospital, placebo-controlled study. Arch. Ophthalmol. 111:657-661, 1993.

40. Schroeder, C., and Jordan, J. Norepinephrine transporter function and human cardiovascular disease. Am. J. Physiol. Heart Circ. Physiol. 303:H1273-H1282, 2012.

41. Langham, M.E., and Diggs, E.M. Quantitative studies of the ocular response to norepinephrine. Exp. Eye Res. 13: 161-171, 1972.

42. Langham, M.E. The intraocular pressure and the pupillary responses of conscious rabbits to racemic erythroalpha-methylnorepinephrine. Exp. Eye Res. 39:781-790, 1984.

43. Pizzirani, S., and Gong, H. Functional anatomy of the outflow facilities. Vet. Clin. North Am. Small Anim. Pract. 45:1101-1126, 2015.

44. Levy, B., Ramirez, N., Novack, G.D., et al. Ocular hypotensive safety and systemic absorption of AR-13324 oph- thalmic solution in normal volunteers. Am. J. Ophthalmol. 159:980-985, 2015.

45. Kopczynski, C., Novack, G.D., Swearingen, D., et al. Ocular hypotensive efficacy, safety and systemic absorption of AR-12286 ophthalmic solution in normal volunteers. Br. J. Ophthalmol. 97:567-572, 2013.

46. Somlyo, A.P., and Somlyo, A.V. Signal transduction by Gproteins, rho-kinase and protein phosphatase to smooth muscle and non-muscle myosin II. J. Physiol. 522 Pt 2:177-185, 2000.

Received: February 17, 2017 Accepted: April 19, 2017

Address correspondence to: Dr. Casey C. Kopczynski Aerie Pharmaceuticals, Inc. 4301 Emperor Boulevard, Suite 400

Durham, NC 27703

E-mail: ckopczynski@aeriepharma.com 